ARTICLE

https://doi.org/10.1038/s41467-019-08876-w

\title{
Rationally designed carbohydrate-occluded epitopes elicit HIV-1 Env-specific antibodies
}

\author{
Cheng Zhu (10) 1,2, Elena Dukhovlinova (10 ${ }^{3}$, Olivia Council ${ }^{3,4}$, Lihua Ping ${ }^{3}$, Edgar M. Faison (1) ${ }^{1}$, Shamit S. Prabhu ${ }^{5}$, \\ E. Lake Potter ${ }^{3}$, Stephen L. Upton ${ }^{1}$, Guowei Yin (10 ${ }^{1}$, James M. Fay ${ }^{1}$, Laura P. Kincer ${ }^{3,4}$, Ean Spielvogel ${ }^{3}$, \\ Sharon L. Campbell ${ }^{1,3}$, S. Rahima Benhabbour ${ }^{5,6}$, Hengming Ke ${ }^{1,3}$, Ronald Swanstrom ${ }^{1,3}$ \& \\ Nikolay V. Dokholyan (1) 1,2,3,6,7
}

An array of carbohydrates masks the HIV-1 surface protein Env, contributing to the evasion of humoral immunity. In most HIV-1 isolates 'glycan holes' occur due to natural sequence variation, potentially revealing the underlying protein surface to the immune system. Here we computationally design epitopes that mimic such surface features (carbohydrate-occluded neutralization epitopes or CONE) of Env through 'epitope transplantation', in which the target region is presented on a carrier protein scaffold with preserved structural properties. Scaffolds displaying the four CONEs are examined for structure and immunogenicity. Crystal structures of two designed proteins reflect the computational models and accurately mimic the native conformations of CONEs. The sera from rabbits immunized with several CONE immunogens display Env binding activity. Our method determines essential structural elements for targets of protective antibodies. The ability to design immunogens with high mimicry to viral proteins also makes possible the exploration of new templates for vaccine development.

\footnotetext{
${ }^{1}$ Department of Biochemistry and Biophysics, University of North Carolina at Chapel Hill, Chapel Hill, NC 27599, USA. ${ }^{2}$ Departments of Pharmacology, Penn State College of Medicine, Hershey, PA 17033-0850, USA. ${ }^{3}$ Lineberger Comprehensive Cancer Center, University of North Carolina at Chapel Hill, Chapel Hill, NC 27599, USA. ${ }^{4}$ Department of Microbiology and Immunology, University of North Carolina at Chapel Hill, Chapel Hill, NC 27599 , USA. ${ }^{5}$ Division of Pharmacoengineering and Molecular Pharmaceutics, Eshelman School of Pharmacy, University of North Carolina at Chapel Hill, Chapel Hill, NC 27599, USA. ${ }^{6}$ UNC-NCSU Joint Department of Biomedical Engineering, University of North Carolina at Chapel Hill, Chapel Hill, NC 27599, USA. ${ }^{7}$ Departments of Biochemistry \& Molecular Biology, Penn State College of Medicine, Hershey, PA 17033-0850, USA. These authors contributed equally: Cheng Zhu, Elena Dukhovlinova. Correspondence and requests for materials should be addressed to R.S. (email: risunc@med.unc.edu) or to N.V.D. (email: dokh@psu.edu)
} 
$\mathrm{H}$ IV-1 carries on a continuous battle with the host immune system $^{1,2}$. As the sole target of neutralizing antibodies, the virion surface protein Env encodes a glycan shield to restrict the antibody access to antigenically conserved sites ${ }^{3,4}$. There are about 30 sites of carbohydrate addition on each HIV-1 Env protomer, and about two-thirds of the N-linked carbohydrates cover the generally conserved outer domain of Env ${ }^{5,6}$. This glycan shield serves as a barrier to an antibody response that would otherwise be directed at surface features of Env ${ }^{7-9}$. Variation in carbohydrate addition sites has been documented wherein $90 \%$ of HIV-1 strains are missing at least one conserved glycosylation site ${ }^{10,11}$. When Env trimers from different HIV-1 clades (A, B, and C) were used as immunogens, the autologous neutralizing antibody response was targeted to the protein face at the site of missing glycans ${ }^{12,13}$. Similarly, the SIV variants missing a dispensable glycan were used to infect macaques and gave rise to an antibody response that targets the exposed area ${ }^{3,14}$. Infection with a virus missing a glycan on the Env $a 2$ helix led to the development of an antibody escape mutant that reacquired the original glycosylation site, suggesting that antibodies to such surface features of Env can provide selective pressure and thus be protective ${ }^{15}$. It is these types of carbohydrate-occluded structural features we refer to as CONEs. We reason that HIV-1 isolates present a collective vulnerability at the surface features under variable glycosylated sites. We set out to exploit their immunogenic nature by eliciting antibodies that interact specifically with individual CONEs.

We previously examined the env gene of HIV-1 subtype C, which accounts for $~ 50 \%$ of new infections worldwide, including samples from acutely and chronically infected individuals ${ }^{10}$. Our results demonstrated moderate conservation of twenty-two Nlinked glycosylation sites on the Env outer face, including positions 130, 230, 234, 289, 332, 337, 356, and 442 (HXB2 numbering), with each glycosylation site appearing in $65-85 \%$ of HIV1 isolates. We find that seventeen of these moderately conserved glycosylation sites cluster around six surface structural features, and we hypothesize the absence of a surface glycan at any one of these CONEs would expose the underlying protein structural elements (Fig. 1a and Supplementary Fig. 1). Analysis of transmitted HIV-1 isolates revealed that $93 \%$ were missing at least one carbohydrate in one of the CONEs, with $80 \%$ missing carbohydrates in two or more CONEs ${ }^{10}$. In previous studies, others have built structural mimetic of CONE 3 (a four-stranded $\beta$ sheet at the base of the V1/V2 loops) and CONE 6 (the CD4 binding site) for structure-guided immunization. Chimeric glycoproteins encoding CONE 3 bind the broadly neutralizing antibody PG916. Protein nanoparticles containing CONE 6 mimetics engage the germline precursors of VRC01-class neutralizing antibodies and direct the evolution of antibodies against the CD4 binding site $^{17,18}$. Here we focus our protein design efforts on four CONEs, including the structural elements of $\beta$ sheet 12/13/22 (CONE 1), a2 helix (CONE 2), loop C (CONE 4), and loop E (CONE 5) (Fig. 1b). Small protein mimics of the CONEs are designed by epitope transplantation and used as immunogens to focus the antibody response ${ }^{19-21}$. Our experimental workflow includes biophysical and structural characterization of the designed proteins, followed by immunogenic evaluation in animal models (Fig. 1c).

\section{Results}

Structure-based immunogen design. Atomic-level details of the fully glycosylated, pre-fusion conformation of the Env trimer have been obtained as crystal and cryo-electron microscopy structures $^{5,22}$. The conformations of the CONEs are well conserved in the structures of Env from clades A, B, C, and G
(Supplementary Fig. 1b). We identified the substructural elements of each CONE based on the BG505 SOSIP.664 trimer structure (Protein Data Bank [PDB]: 4TVP and 4NCO) and adopted the consensus sequence of clade C HIV-1 Env as the reference for the immunogen design ${ }^{23,24}$ (Fig. 1d and Supplementary Fig. 2). The rationales for identifying CONEs include: (i) the change of solvent-exposed area on the Env surface due to absence of glycans. The boundaries of CONE residues can be determined by modeling the interactions between underglycosylated Env and immunoglobulin (Supplementary Fig. 3). (ii) whether the substructures of CONEs can be readily matched to existing scaffolds in PDB (see Methods). (iii) conservation of surface glycan ${ }^{10,11}$. Using a rapid structural motif-mining algorithm Erebus ${ }^{25}$ (Supplementary Fig. 4, workflow), we searched the PDB for scaffolds capable of supporting the disembodied CONE structures (threestranded $\beta$-sheet, $\alpha$-helix, and two separate loops). We estimated the surface matching between scaffolds and CONEs by analysis of root-mean-square deviations (RMSD, 0.5-3.0 $\AA$ ) and selected the top-ranking scaffolds for each CONE (Supplementary Table 1). The surface amino acids of the CONE-like region within each scaffold were replaced by solvent-exposed residues in the consensus sequences of CONEs (Supplementary Figs 2 and 4). For instance, a discontinuous three $\beta$-strand motif was grafted onto CONE 1 scaffolds, while the two helixes on the CONE 2 and scaffold 5 design (C2S5, a similar nomenclature is followed for all designed proteins) displayed the $\alpha 2$ helix-specific residues (Supplementary Fig. 5). The modified scaffold was subsequently relaxed by discrete molecular dynamics ${ }^{26}$.

For each scaffold, multiple designs (86 in total) were generated adopting various combinations of CONE residues and their substitutes in the consensus sequences. We then estimated the change in free energy of these substitutions $\left(\Delta \Delta G_{\text {mut }}\right)$ using the Eris molecular design suite and discarded highly destabilizing mutations (55 designs of $\left.\Delta \Delta G_{\text {mut }}>6 \mathrm{kcal} \mathrm{mol}^{-1}\right)^{27}$. The conformational stabilities of all CONE mimetics were further evaluated through molecular dynamics simulations, which allowed us to rapidly screen the designed protein library and choose the scaffolds that exhibited substantial rigidity around the CONE segment (root-mean-square fluctuations (RMSF) analysis, Supplementary Fig. 6). A recent study of massively parallel protein design demonstrated that structural elements of the most successful designs exhibit high similarity to natural proteins of similar local sequences ${ }^{28}$. Hence, we reasoned that the success of epitope transplantation would correlate with the compatibility between local structure of grafted sequences and their native conformation in Env, whereas higher RMSF of grafted residues indicates that the design explores wider conformational states and likely displays poor agreement to the target structure. Therefore, we filtered out the designs featuring significant plasticity of the grafted epitopes or designated them as alternative scaffolds (21 designs of RMSF $>3.5 \AA$ at CONEs). Overall, three to five designs of each CONE were expressed in Escherichia coli (Supplementary Fig. 5). Of the sixteen candidates tested (one most stable design for each scaffold), eight could be successfully purified as soluble proteins (Supplementary Table 2).

Biophysical characterization of designed proteins. The eight proteins exhibited circular dichroism (CD) spectra consistent with the designed topology (Supplementary Fig. 7a). The stabilities of the designs to thermal denaturation were assessed by CD spectroscopy. Their melting temperatures $\left(T_{\mathrm{m}}\right)$ were in the range of $42-75^{\circ} \mathrm{C}$ (Supplementary Fig. 7b). The CONE 1, 2, and 4 proteins were monomeric in solution (Supplementary Fig. 7c, d), while the C5S3 design displayed rapid exchange between monomeric and dimeric states. We selected the most stable designs 
a Identify CONEs

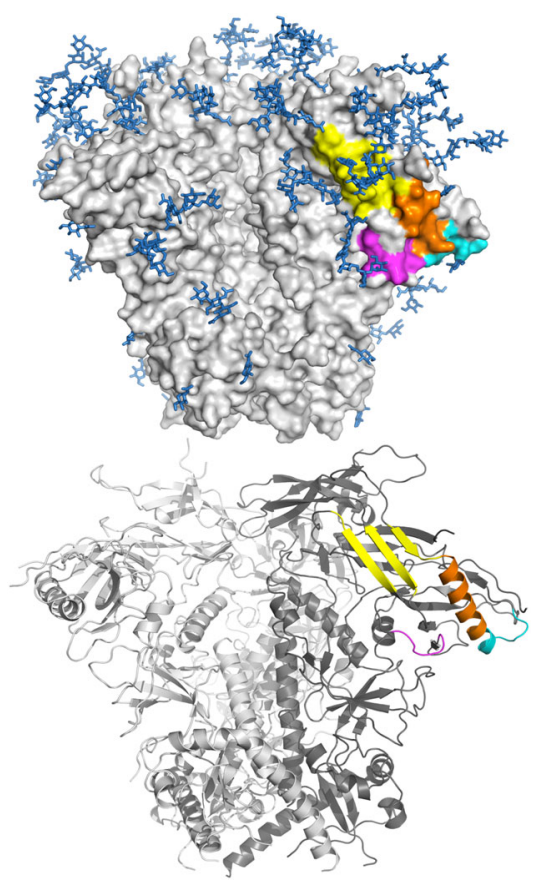

b
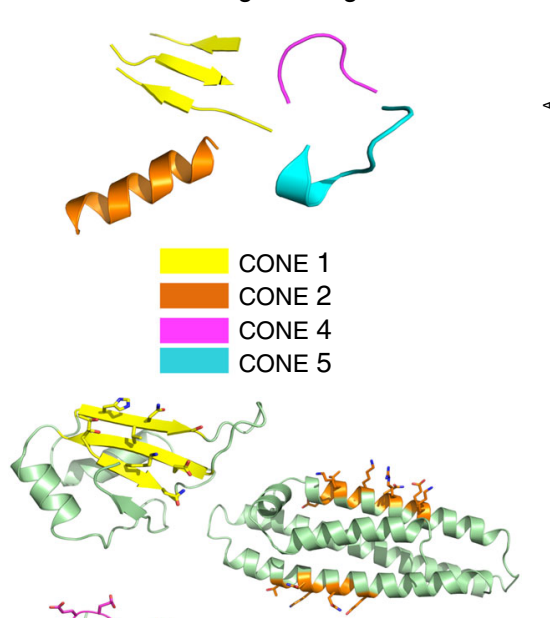

c

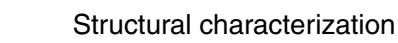

d

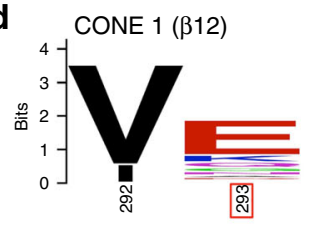

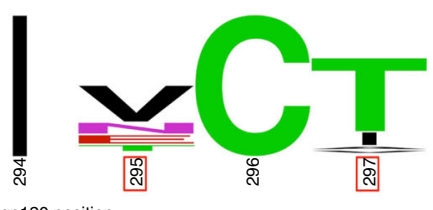

gp120 position
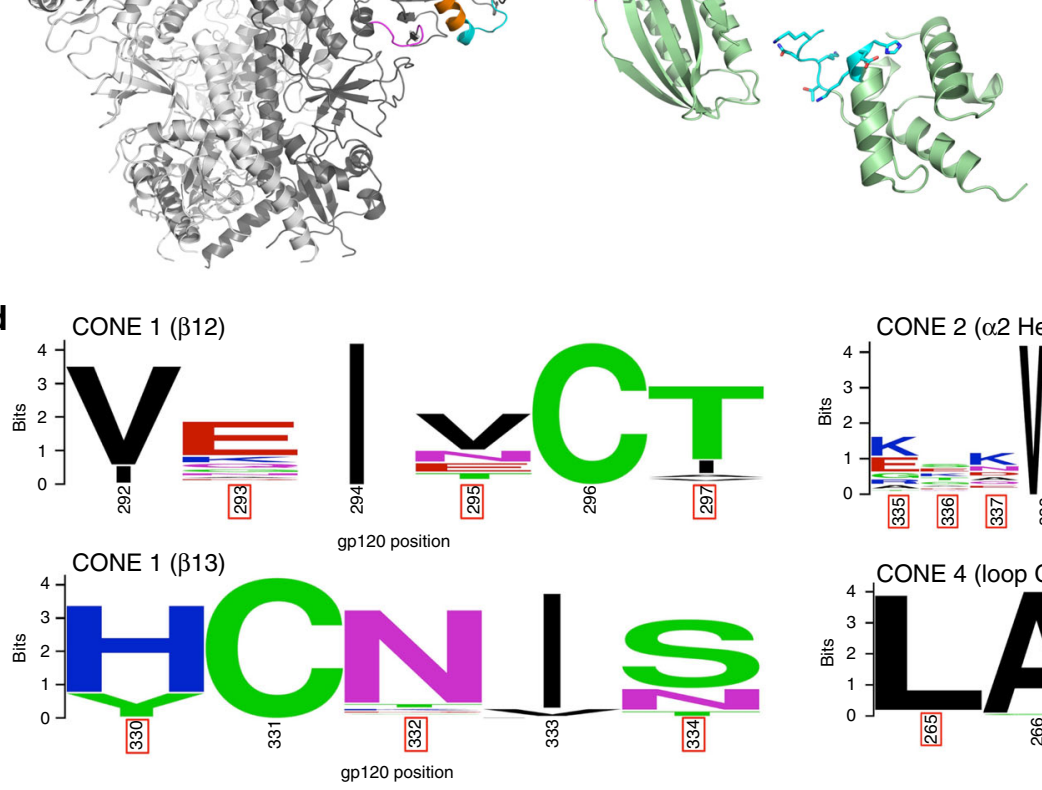

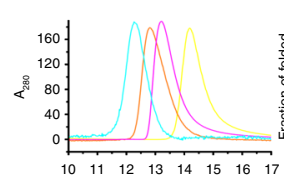

$\begin{array}{lllllllll}10 & 11 & 12 & 13 & 14 & 15 & 16 & 17\end{array}$

Volume (mL)
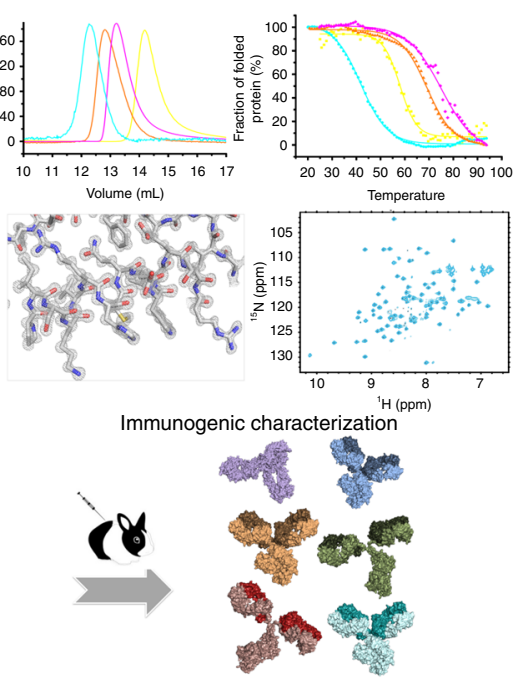

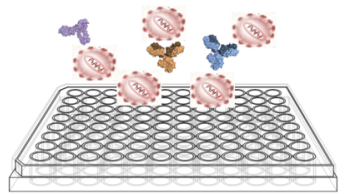

CONE $2(\alpha 2$ Helix)

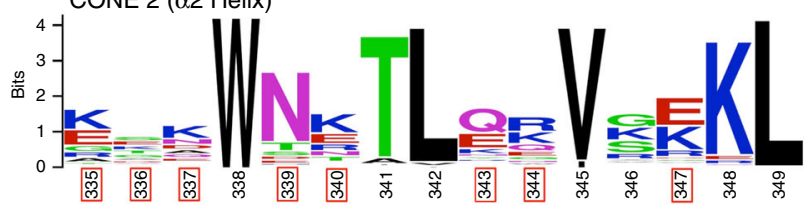

gp120 position

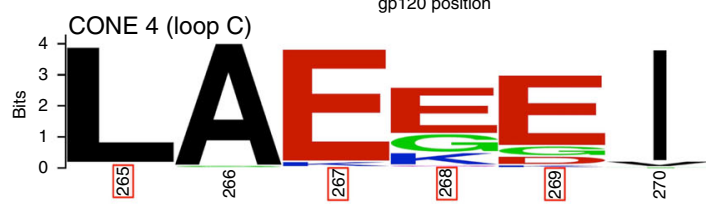

gp120 position

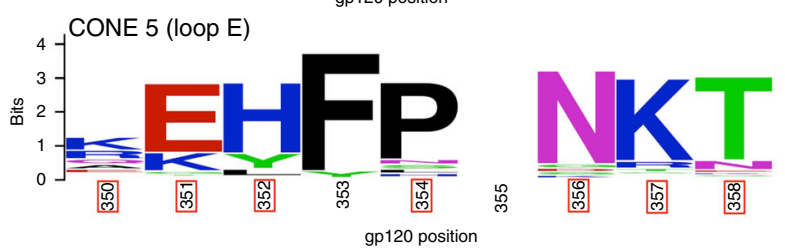

Fig. 1 Rational design of HIV-1 immunogens and elicitation of antibodies targeting the CONEs. a Fully glycosylated Env (upper panel) encodes a shield of glycan (dark blue) masking its conserved surface. In underglycosylated Env (lower panel) the carbohydrate-occluded neutralization epitopes (CONEs) are exposed. The transmitted HIV-1 viruses isolated from infected individuals are typically missing at least one carbohydrate in one CONE (shown in colors, see key in panel b). b Small protein mimics of the CONEs, designed by epitope transplantation, can serve as potential immunogens to focus the antibody response towards CONEs. c The experimental workflow includes biophysical characterization (circular dichroism, size exclusion chromatography), structural characterization (X-ray crystallography, NMR) of designed proteins, and immunogenic evaluation in animal models. d Consensus protein sequences of the CONEs. The site convergence data were derived from 183 Env sequences of clade C HIV-1 isolated from acutely infected patients. The solvent-exposed resides in Env are marked with red boxes

(C1S1, C2S5, and C4S3) for immunization experiments and further structural analysis.

To determine whether the designs recapitulate the native conformations of each CONE, we solved the crystal structures of C2S5 ( $a 2$ helix) and C4S3 (loop C) at resolutions of $2.0 \AA$ and 1.2 $\AA$, respectively (PDB 6CFE and 6CBU, Table 1). The electron density maps revealed that the side chains of the grafted residues were well positioned relative to the computational model
(Supplementary Fig. 8). Comparison with the Env trimer protein revealed a high degree of mimicry: within the epitope region, the Ca RMSDs between the designed proteins and Env were $0.42 \AA$ (C2S5) and $0.34 \AA$ (C4S3), respectively, suggesting that our CONE mimetics accurately display the Env residues (Fig. 2a, b). The C2S5 scaffold is built on a four-helix bundle from apolipoprotein E3. The two helixes used to display the CONE 2 residues were well matched to the $\alpha 2$ helix in terms of the $\mathrm{C} \alpha-\mathrm{C} \beta$ 


\begin{tabular}{|c|c|c|}
\hline & C2S5 & C4S3 \\
\hline \multicolumn{3}{|l|}{ Data collection } \\
\hline Space group & $P 3,21$ & $P 2_{1} 2_{1} 2_{1}$ \\
\hline \multicolumn{3}{|l|}{ Cell dimensions } \\
\hline$a, b, c(\AA)$ & $46.88,46.88,140.42$ & $26.07,57.61,62.94$ \\
\hline$\alpha, \beta, \gamma\left({ }^{\circ}\right)$ & $90,90,120$ & $90,90,90$ \\
\hline \multirow[t]{2}{*}{ Resolution $(\AA)$} & $50.00-2.00$ & $50.00-1.20$ \\
\hline & $(2.03-2.00)^{a}$ & $(1.22-1.20)$ \\
\hline$R_{\text {merge }}$ & $0.064(0.886)$ & $0.056(0.130)$ \\
\hline$|/ \sigma|$ & $13.6(3.7)$ & $18.9(6.9)$ \\
\hline Completeness (\%) & 99.67 & 98.40 \\
\hline Redundancy & $18.0(16.5)$ & $14.1(13.9)$ \\
\hline No. of unique reflections & 12904 & 30098 \\
\hline \multicolumn{3}{|l|}{ Refinement statistics } \\
\hline Resolution $(\AA)$ & $39.00-2.00$ & $42.49-1.20$ \\
\hline No. of reflections & 12849 & 28610 \\
\hline$R_{\text {work }} / R_{\text {free }}(\%)$ & $23.65 / 26.87$ & $14.30 / 15.30$ \\
\hline \multicolumn{3}{|l|}{ No. of atoms } \\
\hline Protein atoms & 2344 & 771 \\
\hline Ligand/ion & 0 & $1\left(\mathrm{SO}_{4}{ }^{2-}\right)$ \\
\hline Water & 17 & 67 \\
\hline \multicolumn{3}{|l|}{ Average $B$-factor $\left(\AA^{2}\right)$} \\
\hline Protein & 70.43 & 7.54 \\
\hline Ligand/ion & NA & 7.69 \\
\hline Water & 48.78 & 14.10 \\
\hline \multicolumn{3}{|l|}{$\begin{array}{l}\text { RMS deviation from } \\
\text { ideality }\end{array}$} \\
\hline Bond lengths $(\AA)$ & 0.004 & 0.006 \\
\hline Bond angles $\left({ }^{\circ}\right)$ & 0.513 & 1.198 \\
\hline \multicolumn{3}{|l|}{ Ramachandran statistics ${ }^{b}$} \\
\hline Favored regions (\%) & 99.28 & 89.20 \\
\hline Allowed regions (\%) & 0.72 & 10.80 \\
\hline Outliers (\%) & 0 & 0 \\
\hline
\end{tabular}

a Highest resolution shell statistics are shown in parentheses

${ }^{b}$ As defined by MolProbity

orientations (Fig. 2a and Supplementary Fig. 8d). The CONE 4 (loop C) residues were grafted onto the C-terminal loop region of an $\alpha / \beta$ mixed protein (Fig. $2 b$ ). A characteristic array of three glutamic acids flanked by hydrophobic residues defines the conformation of CONE 4 loop in Env. Our design largely recapitulates the conformations of two charged side chains (E88 and E89). The hydrophobic residue L86 also adopts a similar conformation to L265 of Env (Fig. 2b). Consistent with the molecular dynamics simulation, we found that the C4S3 loop adopted a relatively rigid structure, as assessed by the low $\mathrm{B}$ factors (8-12 $\AA^{2}$, Supplementary Fig. 6).

We also acquired structural information for C1S1 using nuclear magnetic resonance (NMR). The two-dimensional ${ }^{1} \mathrm{H}$ ${ }^{15} \mathrm{~N}$ heteronuclear single-quantum coherence (HSQC) spectrum suggests that $\mathrm{C} 1 \mathrm{~S} 1$ is well folded in solution (Fig. 2c, right panel). We were able to assign 72 of 77 peaks corresponding to C1S1 residues with the aid of the HNCACB and $\mathrm{CBCA}(\mathrm{CO}) \mathrm{NH}$ spectra (Supplementary Fig. 9). The backbone information derived from $\mathrm{C} \alpha / \mathrm{C} \beta$ chemical shift indicates that $\mathrm{C} 1 \mathrm{~S} 1$ possesses four $\beta$-strands (three from CONE 1 and one from the scaffold protein: hnRNP RNA-binding domain) and two $a$-helices, as expected based on the design model (Fig. 2c, left panel). All CONE 1-associated residues adopted a $\beta$-strand conformation (middle panel).

Immunogenic evaluation of CONE immunogens. We next immunized small groups of rabbits (four to six per group) with the designed immunogens to raise CONE-specific antibodies. Two different immunization strategies were applied: incomplete Freund's adjuvant (FA) and a nanoparticle (NP) formulation without adjuvant (Supplementary Tables 3, 4, Supplementary Fig. 10). In these initial immunization experiments, we sought a qualitative understanding of the nature of the antibodies that can be generated to each CONE. The CONE 1, 2, 4, and 5 mimetics were all immunogenic, giving rise to autologous binding antibodies as determined by enzyme-linked immunosorbent assay (ELISA, Fig. 3a). The FA-associated immunization protocols induced antibodies with the titers more than 10-fold higher than those induced by NP-associated immunization. As a control experiment, we also immunized five rabbits with a synthetic peptide of the CONE 4 sequence (LAEEEI). None of these rabbits could induce antisera of significant titers (Supplementary Table 5), in contrast to the C4S3-immunized rabbits, indicating that for a linear epitope, constraining it in the right conformation with suitable protein scaffolds is favorable for the generation of functional antibodies.

We then evaluated antibody specificity for the CONE-derived epitopes (Supplementary Fig. 11). For each immunogen, an alternative design (C1S5, C2S3, C4S2, and C5S2, Supplementary Table 2) with the same CONE grafted onto a different scaffold protein was used as a control to HIV-specific responses. No HIVspecific antibodies were obtained after immunization with CONE 2 ( $\alpha 2$ helix). The CONE 4 (loop C) and CONE 5 (loop E) immunogens did induce HIV-specific antibodies as assessed by ELISA and western blot assay. The purified IgG fractions of antiCONE 4 and anti-CONE 5 rabbit sera bound to the deglycosylated form of gp120 but not the glycosylated protein (Fig. 3b).

We also analyzed the anti-Env responses of individual rabbit sera in an ELISA assay using the deglycosylated Env SOSIP trimer. We modified the sequence of SOSIP from the original BG505 SOSIP.664 isolate ${ }^{23}$, so that the exposed residues at the CONE regions represent the consensus sequences of Env subtype C. The sera of the rabbits immunized with C1S1 (FA protocol) contained antibodies that bound Env, featuring a significantly elevated response to Env in comparison to the homologous preimmune sera; in contrast, only one animal generated strongbinding antibodies with C1S1-NPs (Supplementary Fig. 12). Most of the animals immunized with C4S3 also generated antibodies that bound to the deglycosylated SOSIP Env protein, whereas no such antibodies were detected in animals immunized with C5S3.

Four C1S1-immunized rabbits generated sera with the highest reactivity to the SOSIP trimer. We tested these serum samples in a virus neutralization assay against reporter HIV-1 viruses, which were pseudotyped using three different env gene clones (682, 1086, and 3037, all subtype C). The viruses expressing the WT Env represent the samples isolated from infected subjects, while the fully glycosylated Env and the mutants represent the CONEconcealed and CONE-revealed samples, respectively (Fig. 4). In this analysis, we accounted for the animal-to-animal variation by comparing responses of the pre-immune serum and the immunization endpoint serum for each rabbit and each virus. The four post-immunization rabbit sera exhibited modest virus inhibitory activity in comparison to the homologous pre-immune serum. The highest responses we observed (50-70\% inhibition) were with virus 3037 (missing N332 and N448 glycans) by the serum of rabbit 481, and with virus 1086 (missing N332 glycan) by the serum of rabbit S1206. Given the low level of virus inhibition associated with these sera it is difficult to distinguish if this activity represents true virus neutralization or some type of nonspecific inhibition of infectivity, although we note this activity is differentially present after immunization. The observed inhibitory activity did not depend critically on the absence of the CONE 1-associated glycans on the Env protein surface. If this 


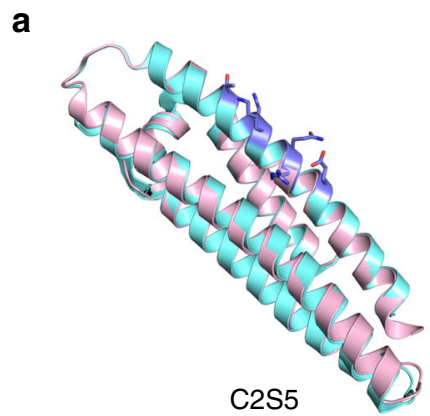

Crystal structure
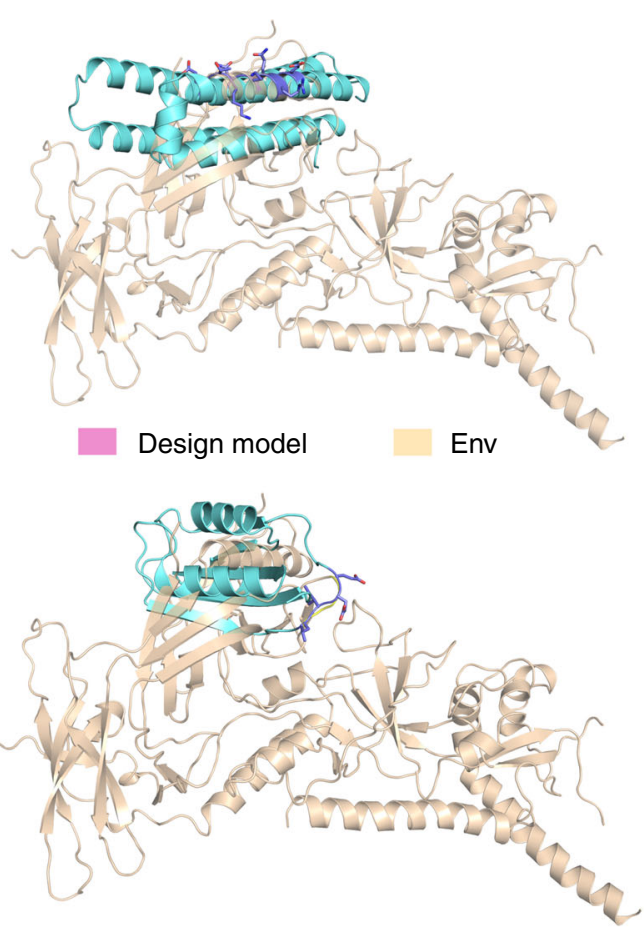
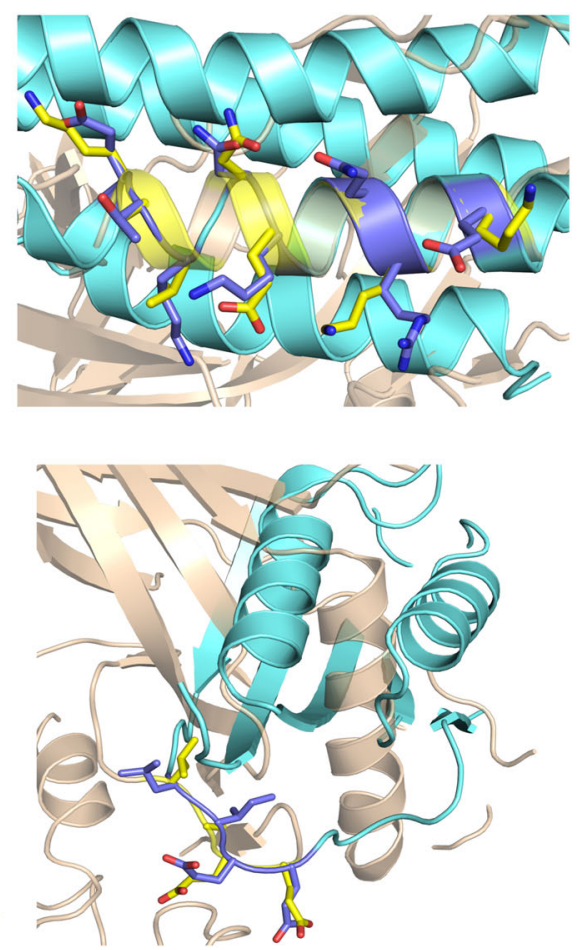

b

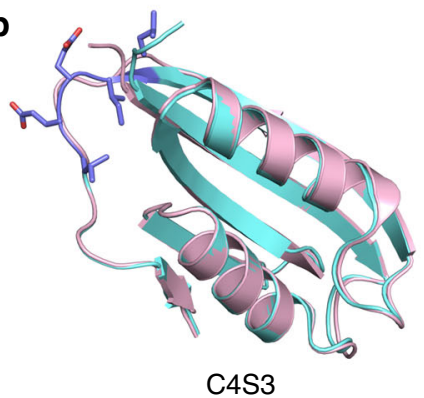

$\alpha$ Helix

$\beta$ Sheet

Loops

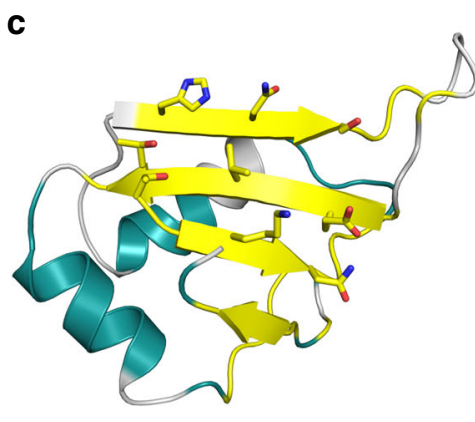

C1S1

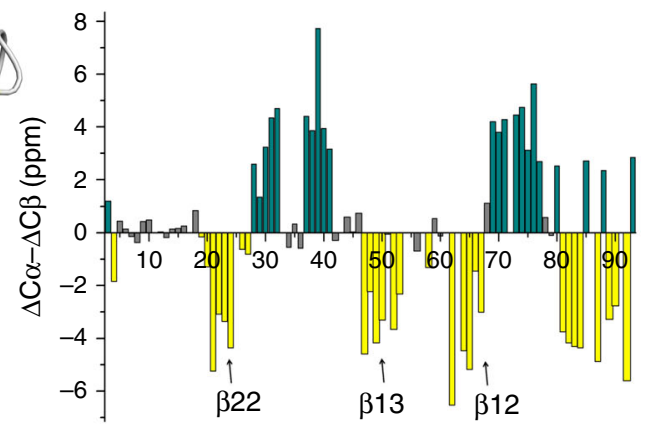

$\beta 22$ $\beta 13$

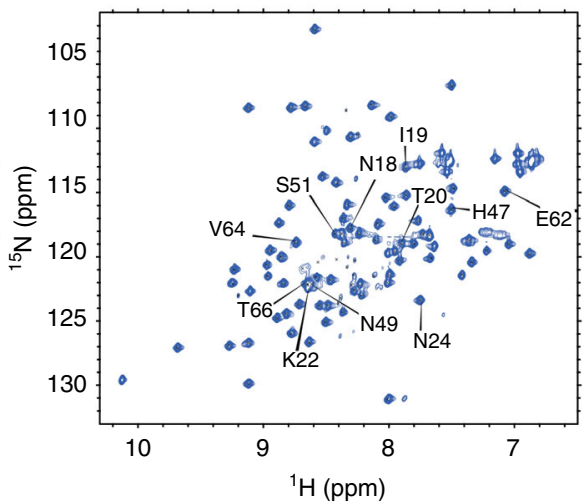

Fig. 2 Structural characterization of designed CONE immunogens. a Crystal structure of C2S5 (PDB 6CFE) aligned to the design model (left) and to the gp120 CONE 2 region (middle, PDB 5FYL, clade A sequence), with the epitope shown as sticks; (Right) Close-up view of the alignment between grafted resides in C2S5 (slate) and the gp120 (yellow) residues in their native conformations. b Crystal structure of C4S3 (PDB 6CBU) with the CONE 4 epitope shown as sticks (slate). c Secondary structure assignment based on solution NMR mapped to the C1S1 design model (left). Plot of the differences of chemical shifts $\Delta \mathrm{C} \alpha-\Delta \mathrm{C} \beta$ (middle) for each residue of C1S1 indicates which residues adopt $\alpha$-helical ( $>1 \mathrm{ppm}$, dark cyan) or $\beta$-sheet (<-1 ppm, yellow) structures. (Right) ${ }^{1} \mathrm{H}_{-15} \mathrm{~N} \mathrm{HSQC}$ spectrum with the assignments to CONE 1 residues indicated. Source data are provided as a Source Data file. See also Supplementary Fig. 9

does represent antibody-mediated neutralization, then the rabbitraised CONE 1-specific antibodies may possess long loops in the complementarity-determining region that are capable of penetrating the glycan shield, as seen in various neutralizing antibodies characterized previously $1,7,8$. In this scenario the occluded surface features may not be immunogenic under the glycan shield, but the corresponding antibodies when they exist may be able to intercalate between structurally dynamic glycan side chains, thus resulting in neutralization.

\section{Discussion}

The strategies that HIV-1 adopts to avoid in vivo neutralization, including hypervariable protein sequences and a glycan coat that occludes the conserved protein surface, confounded the attempts at immunization using Env trimer as antigens ${ }^{29,30}$. Here we described the implementation of an approach based on the observation that less conserved glycosylation sites are occasionally absent due to the intrinsic sequence variation in HIV-1. Our results point to the possibility of generating antibodies that target surface features of Env at 'glycan holes'. We found that binding of anti-CONEs 4 and 5 antibodies to denatured gp120 critically depended on the removal of the proximal glycan. Also, the reactivities of anti-CONEs 1 and 4 antibodies with the SOSIP Env were greatly enhanced after deglycosylation. The magnitude of inhibitory effect upon HIV-1 infectivity was modest with the antiCONE 1 sera tested, although the consistency of the effect against multiple isolates of HIV-1 Env pseudoviruses is indicative of a robust activity. 
a

$\square$ CONE 1-FA $(n=5) \bigcirc$ CONE 1-NP $(n=6)$ CONE 2-NP $(n=4)$

- CONE 4-FA $(n=6) \triangle$ CONE 5-NP $(n=6) \triangle$ CONE 2-NP/2scaffolds $(n=4)$

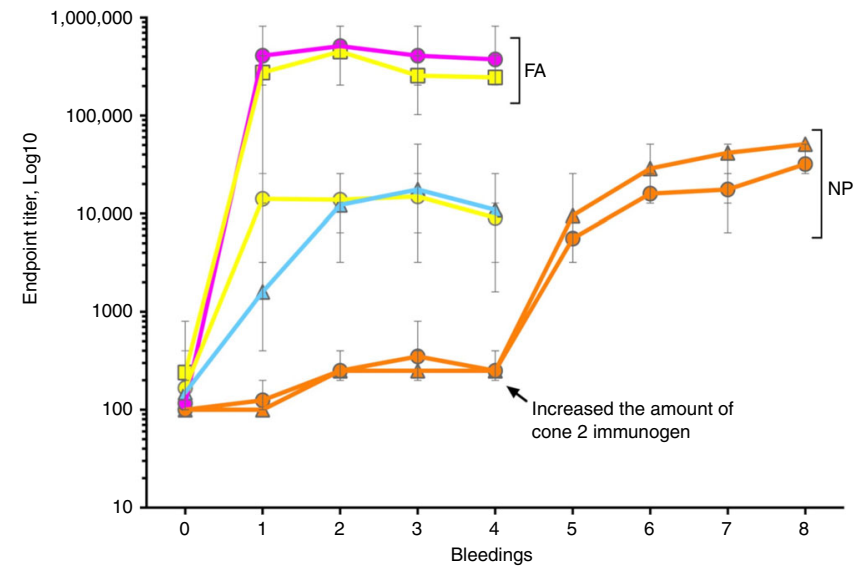

b

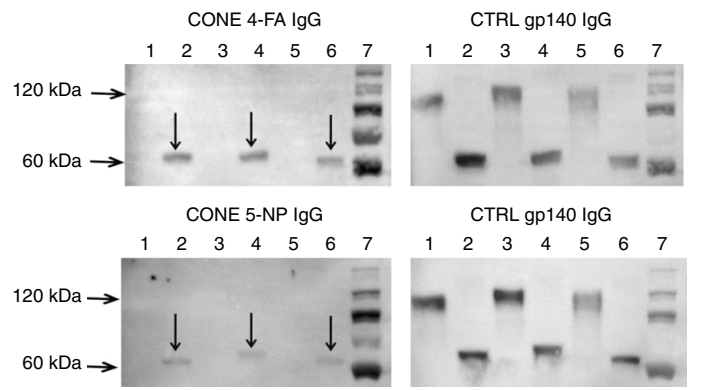

Fig. 3 Characterization of antibodies in the sera from rabbits immunized with CONEs. a Anti-CONE endpoint titers were determined by ELISA during the immunization process. The data represent the mean titers for each group of rabbits. The boost injections were performed monthly, with bleedings performed three weeks after each boost. $n=$ number of rabbits (4-6, indicated for each immunogen). Error bars represent standard deviation. $\mathbf{b}$ Western blots demonstrating the binding of purified rabbit IgG to PNGase-deglycosylated gp120 ( $60 \mathrm{kDa}$ band, lanes 2,4 , and 6 in plots of CONE 4 and 5). No interaction between the IgG and glycosylated gp120 $(\sim 120 \mathrm{kDa}$ band, lanes 1, 3, and 5 in plots of CONE 4 and 5) was observed. (Left) blots treated with IgG purified from rabbits immunized with CONEs; (Right) same blots stripped from CONE IgG and treated with anti-gp140 IgG as a positive control. Lanes: 1-2, 1086 gp120 D7 293F; lanes 3-4, C. TV1C8.2D11 gp120; lanes 5-6, CHO monomer 1086 D7 gp120 K160N; lane 7, PageRuler Plus Prestained Protein Ladder. Source data are provided as a Source Data file

Rational protein design has reinvigorated vaccine design efforts ${ }^{19,31,32}$. Scaffolded immunogens can focus immune responses to known neutralizing antibody determinants ${ }^{31}$ or, as in our work with the HIV-1 CONEs, can facilitate the exploitation of new vulnerable sites. The CONEs reside on an immunogenic 'silent face' of gp120; however, a recent study reported the identification of neutralizing antibody VRC-PG05 that recognizes several CONE 1 residues (E293, N448) as well as CONE 1 glycans (N295, N448) (Supplementary Fig. 13) ${ }^{33}$. This observation suggests the presence of germline antibody precursors that engage CONE-related epitopes. To achieve a functional broadly neutralizing response, a viable approach could be administrating a cocktail of CONE mimetics and SOSIP Env protein missing corresponding CONE glycans in successive and combinatorial boosts, focusing the response on the 'glycan hole'. We expect that rational design of small, thermal-stable CONElike immunogens represents a promising starting point for the development of reproducible vaccines against persisting infections.

\section{Methods}

Determination of the consensus sequence of subtype $\mathbf{C}$ gp120. The consensus amino acid sequence of gp120 subtype $\mathrm{C}$ was obtained by aligning 183 full-length env sequences derived by single genome amplification ${ }^{10}$. The dataset includes: 68 acute env sequences, 65 chronic env sequences, 21 functional env clone sequences from GAVI study, and 29 env sequences from viruses present in a group of participants with low $\mathrm{CD} 4$ counts. The amino acid position was considered a consensus if it was present in $80 \%$ of the isolates. The consensus sequences illustration for Fig. 1d was prepared using WebLogo ${ }^{34,35}$.

We also modified the original sequence of a soluble gp140 protein (SOSIP BG505.664) so that the exposed amino acid residues of the protein that originally belonged to HIV-1 subtype A virus were replaced with residues from HIV-1 subtype $\mathrm{C}$ virus. The modifications were performed for the regions that correspond to CONE $1,2,4$, and 5. Sequence manipulations were performed using BioEdit software and HIV Sequence Database Tools available at Los Alamos National Laboratory website (https://www.hiv.lanl.gov/content/sequence/HIV/mainpage.html).

Computational protein design. The identification of scaffold proteins for transplantation of CONE epitopes made use of the Erebus substructure search server (https://dokhlab.med.psu.edu/erebus) ${ }^{25}$. Query structures for this server were defined as the backbone atoms $(\mathrm{Ca}, \mathrm{N}, \mathrm{C}=\mathrm{O})$ of each individual CONE $(\beta$ 12/13/ 22, a2-helix, loop C, and loop E). We aligned the structures of Env trimer (PDB ID: 4 TVP and 4 NCO for clade A Env, 5FYK for clade B, 5FYJ for clade G) and extracted the coordinates of backbone atoms. The query structures (PDB format) were then provided to Erebus with default search parameters (matching precision 0.5 and minimum weight 'auto'). Erebus scans PDB for matches of structural scaffolds to atom pairs in the query. These resulting scaffolds were ranked based on their RMSD to the query structure (Supplementary Table 1).

Redesign of preexisting scaffolds was accomplished using Eris, a computational platform that automatically performs side-chain repacking and backbone relaxation and calculates the changes in free energy upon mutations $(\Delta \Delta G=$ $\Delta G_{\mathrm{MUT}}-\Delta G_{\mathrm{WT}}$, https://dokhlab.med.psu.edu/eris) ${ }^{27,36}$. The solvent-exposed area of each residue in Env was computed with Naccess 2.1.1 (ASA value $>0.3$ means exposed). The exposed residues within each CONE were introduced into the corresponding scaffolds by Eris. For each single mutation, Eris typically performed $100-300$ calculations to reach a converged distribution of $\Delta \Delta G$ values. The average $\Delta \Delta G$ and its standard deviation were obtained. Highly destabilizing mutations $\left(\Delta \Delta G>6 \mathrm{kcal} \mathrm{mol}^{-1}\right)$ were discarded. The structures of design models were then relaxed and equilibrated by all-atom DMD simulations.

To estimate the structural rigidity of CONE epitopes within designed proteins, MD simulations were performed under physiological conditions (100 ns simulation at $298 \mathrm{~K}, 150 \mathrm{mM} \mathrm{NaCl}$, and neutral $\mathrm{pH}$ ) with Gromacs ${ }^{37}$. The force field CHARMM36 was adopted with the explicit solvent model TIP3P $\mathrm{P}^{38}$. The simulations were performed at constant temperature (V-rescale thermostat) and pressure ( 1 bar, Parrinello-Rahman NPT ensemble). The non-bonded interaction cut-off for electrostatics calculations was set to $10.0 \AA$, and the particle mesh Ewald (PME) method was used in the calculation of long-range electrostatic interactions. Three independent simulations were performed for each design, and the trajectories were analyzed to derive information about the average structure and RMSF.

Protein expression and purification. The genes encoding the designed proteins were synthesized by Biomatik and cloned into BamHI and NcoI restriction sites of pET14b vectors (Invitrogen). All constructs were confirmed by DNA sequencing. E. coli BL21(DE3) pLysE strains transformed with each individual gene were grown to an optimal density (optical density 0.6 at $600 \mathrm{~nm}$ ) in Lysogeny broth, and then gene expression was induced with $1 \mathrm{mM}$ isopropyl- $\beta$-d-thiogalactopyransoide. Proteins expressed with an N-terminal His tag (MGHHHHHHGSENLYFQG) were purified on a HisTrap column (GE Healthcare) and then by size exclusion chromatography (HiPrep 16/60 Sephacryl S-200 HR). Briefly, cell pellets were resuspended in lysis buffer $\left(20 \mathrm{mM} \mathrm{NaH} \mathrm{PO}_{4} / \mathrm{Na}_{2} \mathrm{HPO}_{4}, 40 \mathrm{mM}\right.$ imidazol, $100 \mathrm{mM} \mathrm{NaCl}, 5 \mathrm{mM} \beta$-mercaptoethanol, $\mathrm{pH}$ 7.4) with protease inhibitors (phenylmethylsulfonyl fluoride and pepstatin A) and lysed by sonication. The supernatant containing protein components was separated from precipitate by centrifugation at $24,000 \times g$ for $30 \mathrm{~min}$, passed through $0.22-\mu \mathrm{m}$ filter (Millipore) and then loaded onto a HisTrap column. Proteins were eluted with a gradient (5-90\%, $500 \mathrm{mM}$ imidazol as $100 \%$ ) of imidazol in $20 \mathrm{mM} \mathrm{NaH} \mathrm{PO}_{4} / \mathrm{Na}_{2} \mathrm{HPO}_{4}$, $100 \mathrm{mM} \mathrm{NaCl}$, pH 7.4. For the Sephacryl 200 column $50 \mathrm{mM} \mathrm{NaH} \mathrm{PO}_{4} / \mathrm{Na}_{2} \mathrm{HPO}_{4}$ and $150 \mathrm{mM} \mathrm{NaCl}(\mathrm{pH} 7.4)$ was used as running buffer. The His tag was removed by TEV protease (Sigma-Aldrich) following the manufacturer's procedure. The cleaved proteins were enriched in flow through of the HisTrap column and were further purified through a HiLoad 16/600 Superdex 200 preparatory-grade column (GE Healthcare). The His tags were not removed from proteins conjugated to nanoparticles for immunization.

For NMR measurements, E. coli BL21(DE3) pLysE strains containing the C1S1 gene (in pET14b) were grown in $\mathrm{M} 9$ minimal medium with $1.0 \mathrm{~g} \mathrm{~L}^{-1}{ }^{15} \mathrm{NH}_{4} \mathrm{Cl}$ and 


\section{Rabbit S1201.C1 FA Dost-immunization Rabbit S1206.C1 FA}
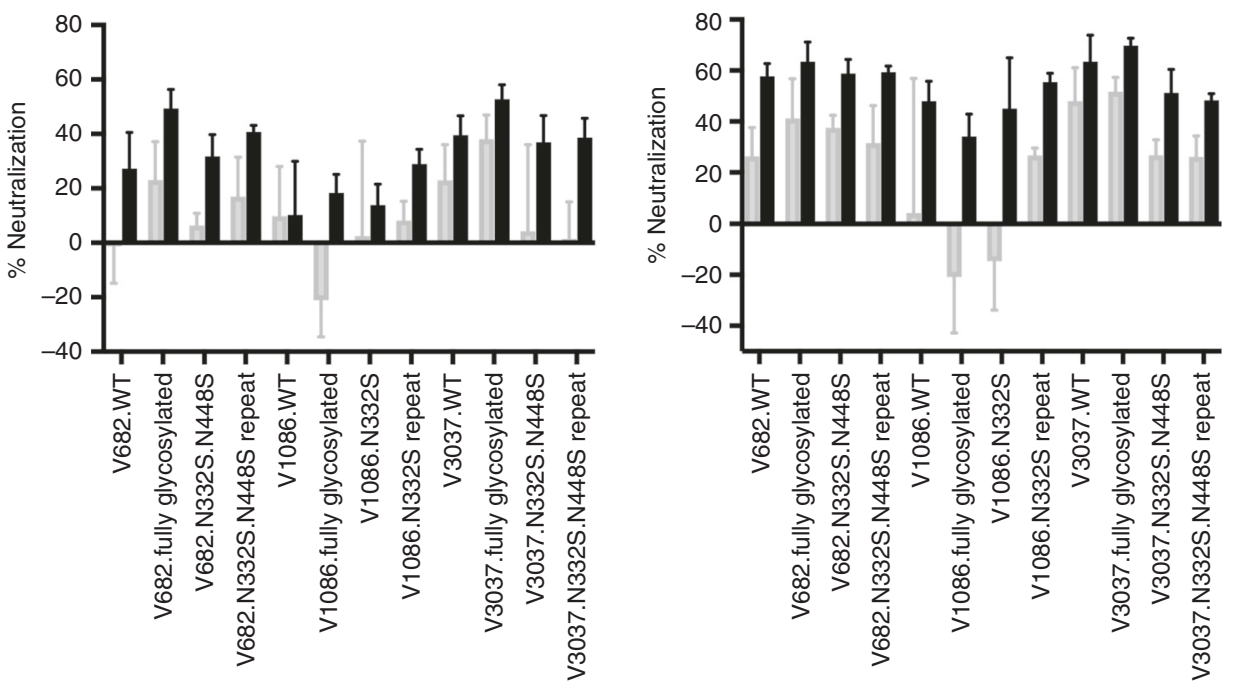

Rabbit S1207.C1 FA

Pre-immunization

Post-immunization

Rabbit 481.C1 NP
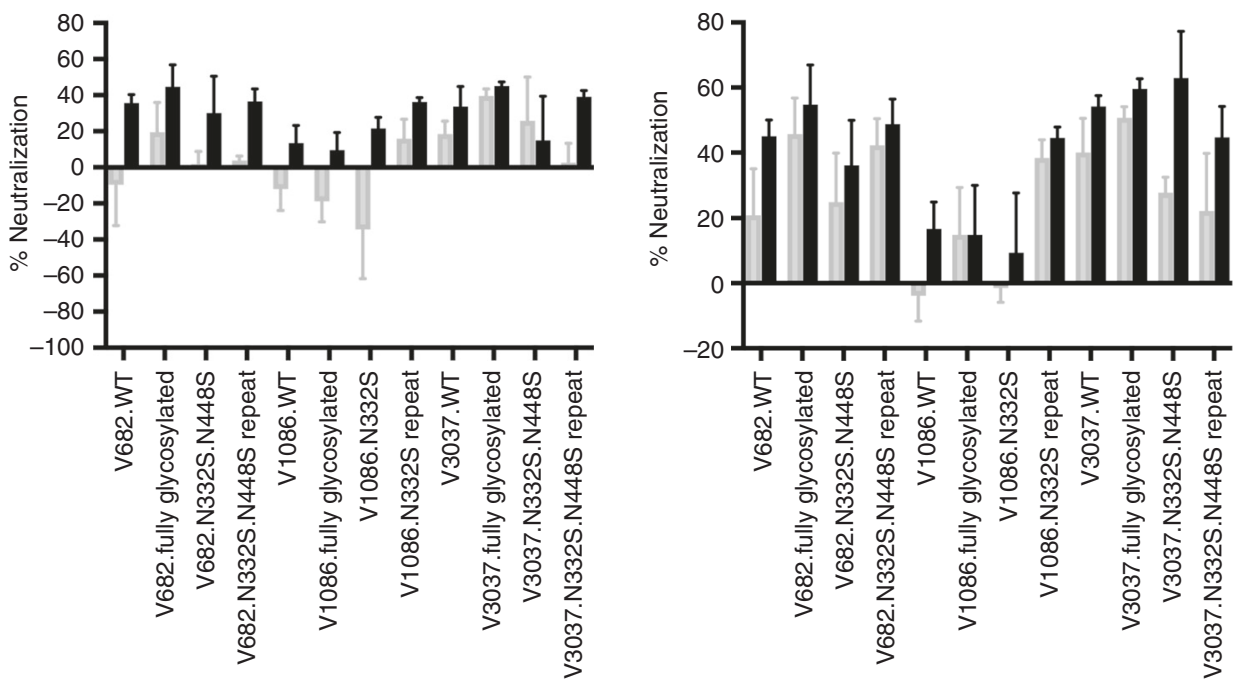

Fig. 4 Anti-CONE 1 rabbit sera have moderate inhibitory activity against pseudotyped HIV-1. Pre- and post-immunization sera were heat inactivated, diluted 1:10 in media, and incubated with pseudotyped HIV-1 for $2 \mathrm{~h}$ before addition to TZM-bl cell culture. The inducible luciferase activity was quantified as a surrogate of viral infectivity. Percent neutralization (\%) was determined by subtracting the pre- and post-immunization relative light units (RLU) from the virus-only RLU (not shown) and dividing the differences by the virus-only RLU. Each experiment was repeated three times. Pseudotyped HIV- 1 isolates included in the assays: V682, V1086, and V3037. Rabbits ID: S1201, S1206, S1207 and 481. $n=3$ independent experiments. Error bars represent standard deviation. Source data are provided as a Source Data file

$2.0 \mathrm{~g} \mathrm{~L}^{-1}{ }^{13} \mathrm{C}$ dextrose (Cambridge Isotope Laboratories, Inc.). Proteins were expressed and purified following the same procedure as used for those obtained from cells grown in Lysogeny broth medium.

Chemicals and enzymes were purchased from Sigma-Aldrich unless otherwise indicated. Protein concentrations were determined on a NanoDrop spectrophotometer using absorption at $280 \mathrm{~nm}$ (Thermo Scientific).

Biophysical characterization. CD spectroscopy data was collected using a Chirascan Plus instrument (Applied Photophysics, MA). The protein samples were dialyzed against $50 \mathrm{mM}$ phosphate buffer $(\mathrm{pH} 7.4)$ and diluted to $0.2 \mathrm{mg} \mathrm{mL}^{-1}$ before analysis. CD spectra were measured from 260 to $185 \mathrm{~nm}$ at $20^{\circ} \mathrm{C}$ with 50,000 readings taken with $0.5-\mathrm{nm}$ increment. Melting curves were monitored from 20 to $94^{\circ} \mathrm{C}$ at $220 \mathrm{~nm}$ and fitted to a two-state folding model for the estimation of melting temperatures ${ }^{39}$.

The protein samples for size exclusion analysis $(10 \mu \mathrm{M}$ protein in $40 \mathrm{mM}$ $\mathrm{Na}_{2} \mathrm{HPO}_{4} / \mathrm{NaH}_{2} \mathrm{PO}_{4}, 100 \mathrm{mM} \mathrm{NaCl}, \mathrm{pH}$ 7.4) were loaded onto a Superdex $20010 /$ 300 GL column (GE Healthcare, PA) and eluted with the same PBS buffer at a flow rate of $0.4 \mathrm{~mL} / \mathrm{min}$. UV absorption at $280 \mathrm{~nm}$ was monitored. Three molecular weight markers were also analyzed: cytochrome $\mathrm{C}(12.4 \mathrm{kDa})$, aprotinin $(6512 \mathrm{Da})$, and vitamin B12 (1355 Da). The log of molecular weight versus elution volume for those proteins was plotted for the column and used to calculate the apparent molecular weight of designed proteins.

Crystallization, data collection, phasing, and refinement. Protein samples for crystallization (10-50 $\mathrm{mg} \mathrm{mL}^{-1}$ in $20 \mathrm{mM}$ Tris, $150 \mathrm{mM} \mathrm{NaCl}$, pH 8.0) were prepared by column chromatography and ultrafiltration. Sparse matrix screens in $96-$ well sitting drops were performed on Rigaku Phoenix Liquid Handler with MCSG Crystallization Suite. Crystallization conditions were then optimized for C2S5 and C4S3 in 24-well hanging drops. C2S5 was crystallized in $16 \%(\mathrm{w} / \mathrm{v})$ polyethylene glycol 20000, $100 \mathrm{mM}$ MES, pH 6.5. C4S3 was crystallized in 30\% (w/v) polyethylene glycol 3350, $200 \mathrm{mM}$ Bis-tris $\mathrm{pH} 6.5$, and $200 \mathrm{mM} \mathrm{LiSO}_{4}$. Crystals were cryoprotected in the reservoir solution supplemented with $10 \%(\mathrm{v} / \mathrm{v})$ glycerol, then flash frozen and stored in liquid nitrogen. The crystals were checked for high quality X-ray diffraction using Rigaku Saturn $944+$ CDD with ACTOR sample 
changing robot. Diffraction data was then collected on Advanced Photon Source (Argonne National Laboratory) at beamlines 22-ID and 22-BM (wavelength $0.9782 \AA$ ) and processed on HKL2000 ${ }^{40}$. The structures of C2S5 and C4S3 were solved by molecular replacement with Phaser of CCP4i and PHENIX ${ }^{41,42}$. Briefly, the crystal structures of the scaffold proteins (PDB ID 1BZ4 for C2S5 and 2W4C for C4S3) were used as search models. The structures were built and manually adjusted in Coot and then refined by Refmac5 (or by PHENIX with Composite omit map and TLS refinement options). The structures were validated using PDB validation server, Molprobity and Chiron server (https://dokhlab.med.psu.edu/ chiron ${ }^{26,43}$. Data collection and final refinement statistics are shown in Table 1.

NMR. For NMR measurements, ${ }^{13} \mathrm{C}$ and ${ }^{15} \mathrm{~N}$-enriched C1S1 protein $(1 \mathrm{mM})$ was exchanged into NMR buffer $\left(20 \mathrm{mM} \mathrm{Na}_{2} \mathrm{HPO}_{4} / \mathrm{NaH}_{2} \mathrm{PO}_{4} \mathrm{pH}\right.$ 6.0). Five percent (v/v) $\mathrm{D}_{2} \mathrm{O}$ and $10 \mu \mathrm{M}$ DSS (4,4-dimethyl-4-silapentane-1-sulfonic acid) were added to the protein solution. NMR spectra were acquired at $25^{\circ} \mathrm{C}$ on a Bruker Avance III 850 NMR spectrometer. $2 \mathrm{D}^{1} \mathrm{H}_{-}{ }^{15} \mathrm{~N}$ HSQC experiments were recorded using 16 scans per increment and a recovery delay of $1.0 \mathrm{~s}$ with 2048 and 256 complex points in the direct and indirect dimensions, respectively. Spectral widths used were $7911.393 \mathrm{~Hz}\left({ }^{1} \mathrm{H}\right)$ and $2152.949\left({ }^{15} \mathrm{~N}\right) \mathrm{Hz}$. Average ${ }^{1} \mathrm{H}_{-}{ }^{15} \mathrm{~N}$ chemical shift perturbations were calculated according to the square root of $\left(\left(\Delta \sigma^{1} \mathrm{H}\right)^{2}+\left(\Delta \sigma^{15} \mathrm{~N}\right)^{2} / 25\right)$, where $\Delta \sigma^{1} \mathrm{H}$ and $\Delta \sigma^{15} \mathrm{~N}$ are the observed changes in ${ }^{1} \mathrm{H}$ and ${ }^{15} \mathrm{~N}$ chemical shifts.

${ }^{1} \mathrm{H}_{-}{ }^{15} \mathrm{~N}$ HSQC spectra allow for the detection of protons directly bonded to a ${ }^{15} \mathrm{~N}$, including both backbone and side-chain $\mathrm{NH}$ resonances. An NH resonance can be detected for every residue except for proline and the spectrum contains a 'fingerprint' of the protein backbone. Backbone resonance assignments of C1S1 were obtained by analysis of $\mathrm{HNCACB}$ and $\mathrm{CBCA}(\mathrm{CO}) \mathrm{NH}$ spectra recorded on ${ }^{13} \mathrm{C}$ and ${ }^{15} \mathrm{~N}$-labeled $\mathrm{C} 1 \mathrm{~S} 1$ at the same concentration employed for 2D HSQC experiments. The spectra were recorded with $2048\left({ }^{1} \mathrm{H}\right), 64\left({ }^{15} \mathrm{~N}\right)$, and $128\left({ }^{13} \mathrm{C}\right)$ complex points. Spectral widths were $10204.082 \mathrm{~Hz}\left({ }^{1} \mathrm{H}\right), 2929.115 \mathrm{~Hz}\left({ }^{15} \mathrm{~N}\right)$, and $12820.513 \mathrm{~Hz}\left({ }^{13} \mathrm{C}\right)$.

The assignments of $\mathrm{Ca}, \mathrm{C} \beta, \mathrm{N}$, and $\mathrm{HN}$ chemical shifts were performed with an iterative procedure using the program MARS and manual inspection ${ }^{44}$. For chemical shift indexing (CSI), $\Delta \mathrm{C} \alpha$ and $\Delta \mathrm{C} \beta$ values were calculated by subtracting experiment chemical shifts of $\mathrm{C} \alpha$ and $\mathrm{C} \beta$ from random coil values obtained from the ncIDP server ${ }^{45}$. The value of $\Delta \mathrm{C} \alpha-\Delta \mathrm{C} \beta$ was calculated to cancel the systematic offset contained in $\Delta \mathrm{C} \alpha$ and $\Delta \mathrm{C} \beta$ and then used to predict secondary structure. G17, G25, G43, G57, G61, G63, and G86 have no $C \beta$ and their $\Delta \mathrm{C} \alpha-\Delta C \beta$ values were not calculated. Spectra were processed and analyzed using NMRPipe (NIDDK, National Institutes of Health) and Sparky (University of California, San Francisco).

General immunization procedure. Immunogen injections and animal handling were performed by the Division of Laboratory Animal Medicine staff of UNCChapel Hill. All work with animals followed protocols that were approved by the UNC Chapel Hill Institutional Animal Care and Use Committee. Intra-muscular injections were performed on 8-12-week-old New Zealand white female rabbits $(2.5-3.0 \mathrm{~kg})$ obtained from Robinson Services. The immunization protocols are summarized in Supplementary Table 3. The immunization scheme was an initial dose of $300 \mu \mathrm{g}$ of each CONE followed by boost injections, supplemented with either incomplete Freund's adjuvant according to the standard protocol, or nickelconjugated nanoparticles without additional adjuvant. Immunogen boost injections with the same amount of protein were performed 3 weeks apart. The immunization of loop C peptide was performed by the Custom Antibodies department of Thermo Fisher Scientific company.

For CONE 2 immunization, two changes were introduced. First, the single scaffold-immunogen (C2S5) was compared to two scaffold-immunogens (C2S5 + C2S3) approach. In the latter approach, we alternated injections of the proteins with the same structure and HIV-specific sequence presented on different scaffolds. Second, we assessed the possibility to use the saponin-based adjuvant Matrix- $\mathrm{M}^{\mathrm{m}}$ (Novavax $\mathrm{AB}$ ) as a substitute for the nanoparticles. Matrix-M adjuvant was kindly provided by Novavax, Inc. For the first 8 weeks, $30 \mu \mathrm{g}$ of protein were given at each injection. Lower antibody titers were observed than previously obtained with $300 \mu \mathrm{g}$ of conjugated protein; therefore, the CONE 2 immunization plan was amended. After 8 weeks the amount of immunogen was increased from initial 30 $\mu \mathrm{g}$ protein to $300 \mu \mathrm{g}$ conjugated on nanoparticles, without an adjuvant. This change of protein amount is noted in Fig. 3a.

\section{Immunization with nanoparticles. Nickel nanoparticles (NPs) were prepared} from warm oil/water $(\mathrm{o} / \mathrm{w})$ microemulsion precursors following a reported procedure $^{46,47}$. In the optimized formulation, Brij $78(1.75 \mathrm{mg})$, Brij $78-\mathrm{NTA}-\mathrm{Ni}$ $(1.75 \mathrm{mg})$, TPGS $(1.5 \mathrm{mg})$, and Miglyol $812(2.5 \mathrm{mg})$ were weighed into a $7 \mathrm{~mL}$ glass vial and heated in a water bath to $65^{\circ} \mathrm{C}$ to melt and blend all excipients. A small amount of ethanol $(100 \mu \mathrm{L})$ was added to the melted excipients and the solution was swirled to result in a homogenous mixture. The ethanol was removed completely using a stream of nitrogen and the vial was transferred to a water bath at $65^{\circ} \mathrm{C}$. To the mixture of melted oil and surfactants was added $1 \mathrm{~mL}$ of filtered and deionized water pre-heated at $65^{\circ} \mathrm{C}$, and the solution was stirred for $30 \mathrm{~min}$ at $65^{\circ} \mathrm{C}$ then cooled to room temperature.
NPs ( $1 \mathrm{~mL}$ batches, $n=3$ for each protein concentration) were characterized for particle size (NanoSight), zeta potential, and Ni content Ni content (ICP-MS) prior to addition of protein. The Ni-NPs $(0.5 \mathrm{~mL})$ were incubated with the corresponding amount of His-tagged protein (C1S1, C2S5, C4S3, or C5S3) at $4{ }^{\circ} \mathrm{C}$ overnight. Final protein concentrations added to $0.5 \mathrm{~mL}$ of Ni-NPs were: $150 \mu \mathrm{gLL}^{-1}, 240 \mu \mathrm{gL}^{-1}$, $300 \mu \mathrm{g} \mathrm{mL}^{-1}, 400 \mu \mathrm{g} \mathrm{mL}^{-1}$, and $500 \mu \mathrm{g} \mathrm{mL}^{-1}$. Free His-tagged protein was removed by spin filtration using VIVASPIN 500 ultrafiltration tubes ( $300 \mathrm{kDa}$ MWCO). Sample containing protein and NPs was transferred to a spin filtration tube and spun at 16,000 rcf for $30 \mathrm{~min}$ to remove free unconjugated protein. Purified samples were analyzed by UV absorbance at $280 \mathrm{~nm}$ before and after spin filtration to quantify the percent conjugation of His-tagged protein to NPs at each concentration $(n=3)$. The UV absorbance was measured using a BioTek Synergy 2 UV Spectrometer (Winooski) at a wavelength of $280 \mathrm{~nm}$.

Polyoxyethylene (20) stearyl ether (Brij 78) was purchased from Uniqema (Wilmington, DE). D-alpha-tocopheryl polyethylene glycol 1000 succinate (TPGS) was purchased from Eastman Chemicals (Kingsport, TN). Miglyol 812 is a mixed caprylic (C8:0) and capric (C10:0) fatty acid triglyceride and was purchased from Sasol (Witten, Germany). Brij 78-NTA-Ni was synthesized by Dr. Benhabbour using a reported procedure ${ }^{46}$. Acetonitrile $\left(\mathrm{CH}_{3} \mathrm{CN}\right)$, dichloromethane $\left(\mathrm{CH}_{2} \mathrm{Cl}_{2}\right)$, and ethanol (EtOH) were purchased from Fisher Scientific.

Particle size and zeta potential. NPs samples were run on a NanoSight NS500. All samples were diluted to a concentration between $1 \times 10^{8}$ and $5 \times 10^{8}$ particles per $\mathrm{mL}$ in deionized $\mathrm{H}_{2} \mathrm{O}$. Five 60 -s videos were taken of each sample to capture particles movement. The NanoSight software tracked the particles individually and using the Stokes-Einstein equation, calculated the hydrodynamic diameters. The zeta potential of NPs was measure in PBS (pH 7.4) using a Malvern Zeta Sizer 2000 (Malvern Instruments).

ICP-MS analysis. Nickel content was quantified by inductively coupled plasma mass spectrometry (ICP-MS). The Agilent 7500cx ICPMS is outfitted with an octapole reaction cell (ORC) and a high matrix introduction (HMI) system. Standard operating conditions were RF Power $1550 \mathrm{~W}$, argon flows and plasma gas flow $15 \mathrm{~L} \mathrm{~min}^{-1}$, carrier gas flow $1.03 \mathrm{~L} \mathrm{~min}^{-1}$, makeup gas $0.15 \mathrm{~L} \mathrm{~min}^{-1}$ and sampling depth was $8.0 \mathrm{~mm}$. All solutions were prepared using $18 \mathrm{M} \Omega$ deionized water and trace metal grade nitric acid (SCP Science). The instrument was tuned daily to maximize sensitivity and minimize production of oxides and doubly charged ions. Sample flow rate was $330 \mu \mathrm{L} \mathrm{min}^{-1}$ through a Mienhard TRP-50A0.5 nebulizer and the Scott double pass spray chamber was cooled to $2{ }^{\circ} \mathrm{C}$. Helium flowed at $4 \mathrm{~mL} \mathrm{~min}^{-1}$ through the ORC to eliminate isobaric interferences, ${ }^{44} \mathrm{Ca}^{16} \mathrm{O}^{+}$and ${ }^{23} \mathrm{Na}^{37} \mathrm{Cl}^{+}$, of ${ }^{60} \mathrm{Ni}$. Standards were prepared using single element standards purchased from High Purity Standards. Scandium was used as internal standard and introduced continuously through a tee junction. Ions ${ }^{45} \mathrm{Sc}$ (internal standard) and ${ }^{60} \mathrm{Ni}$ were monitored in a peak hopping mode, using a 100 -ms dwell time, and eight replicates were measured. The Ni standard curve included 13 concentrations levels in the range of $0.5-1000 \mathrm{ppb}$. This spanned the concentration range of all samples. The standard dataset was fitted to a linear curve. The coefficient of correlation was 0.999 . Percent error in calculated concentrations was $<5 \%$. For quantitation of $\mathrm{Ni}$ in the NPs, preparation included removal of the water from the NPs and resuspension in $2 \% \mathrm{HNO}_{3}$ solution.

TEM imaging. Preparations of NPs, Matrix-M adjuvant, and protein alone and in combination were negatively stained with $2 \%$ sodium phosphotungstate, $\mathrm{pH} 7.0$. Five microliters of suspension was applied to a glow-discharged formvar/carboncoated 400 mesh copper grid and allowed to adsorb for 1 min or 5 min depending on concentration. Grids were briefly floated on droplets of deionized water twice to remove buffer salts and were then transferred to a $25-\mu$ d droplet of $2 \%$ sodium phosphotungstate, $\mathrm{pH} 7.0$ for $30 \mathrm{~s}$. Excess stain was removed by blotting with filter paper and the grids were air dried. Grids were observed with a JEOL JEM-1230 transmission electron microscope (JEOL USA) operating at $80 \mathrm{kV}$, and digital images were acquired using a Gatan Orius SC1000 CCD camera and Gatan Microscopy Suite 3.0 software (Gatan, Inc.).

ELISA. The autologous and heterologous binding properties of antibodies to the CONE immunogens and SOSIP Env were tested using the Protein Detector Peroxidase ELISA Kit, Anti-Rabbit IgG (KPL/Sera Care Life Sciences). The ELISA assay was performed according to the manufacturer's protocol; minor modifications included plate coating overnight at $4{ }^{\circ} \mathrm{C}$ and color development for $1 \mathrm{~h}$ before addition of a stop solution. Absorbance levels were measured at $405 \mathrm{~nm}$. CONE immunogens coated on microwell plates were exposed to serial dilutions (1:200 to $1: 256,000)$ of the rabbit sera and the lowest titer was determined at the absorbance level $>0.4$, which was the two times recommended maximum background value for this kit. The primary immunogen and an alternative scaffold were used to confirm the specificity of the immune response. For the SOSIP ELISA assay, the modified gp140 SOSIP-C protein was used. The protein was produced in $293 \mathrm{~F}$ cell line at the UNC Protein Expression \& Purification Core Facility and deglycosylated in native conditions by incubation for $24 \mathrm{~h}$ with PNGase F according to the manufacturer's protocol (New England Biolabs). 
Western blot. Total rabbit IgG was purified from each animal using rProtein A GraviTrap kit (GE) according to the kit protocol, dialyzed against PBS buffer, and diluted to equal amount per CONE immunization group. The gp120 proteins were deglycosylated using PNGase F in SDS buffer (New England Biolabs). Ten percent polyacrylamide gels and standard western blot protocol with SuperBock blocking reagent (ThermoFisher) was applied. The modified gp140 SOSIP-C proteins were produced at UNC Protein Expression \& Purification Core. The amount of any protein loaded per lane was $400 \mathrm{ng}$. Purified IgG pools from immunized animals $\left(1 \mathrm{mg} \mathrm{ml}^{-1}\right)$ were used as primary antibodies at a dilution of 1:1500. HRP goat anti-rabbit antibody (Thermo Fisher Cat \#32460) was used as secondary antibody at a dilution 1:12500. The fluorescence signal was detected by Amersham ECL Western Blotting Detection Kit (GE) using a BioRad Chemidoc imager. PageRuler Plus Prestained Ladder was used for band size discrimination. To confirm the successful transfer of the gp120 proteins, the blots were stripped using Restore Western Blot Stripping Buffer (ThermoFisher) and restained with anti-gp140 rabbit IgG solution $\left(1 \mathrm{mg} \mathrm{ml}^{-1}\right.$ and $1: 12,500$ dilution) that targeted a variety of epitopes on gp120 and served as our positive control for both glycosylated and deglycosylated proteins. Scans of all blots were supplied in the Source Data file.

Neutralization assays. To assess neutralizing properties of raised antibodies, we used a panel of HIV-1 pseudoviruses that expressed isolate-specific Env proteins, incubated the virus with rabbit serum, and assessed viral infectivity in the luciferase-expressing TZM-bl cells using a standard protocol (https://www.hiv. lanl.gov/content/nab-reference-strains/html/Protocol-for-NeutralizingAntibody-Assay-for-HIV-1-in-TZMbl-cells_Apr2017.pdf). TZM-bl cells were obtained from NIH AIDS Reagent program (cat. \# 8129). Based on similarities to CONE immunogens, we chose the following HIV-1 isolates with corresponding GenBank IDs: 0665 (GB\# KC894076), 0682 (GB\# KC894077), 1086 (GB\# KC894079), 3003 (GB\# KC894087), and 3037 (GB\# KC894098). In those cases where the natural isolate lacked one or more of the relatively conserved glycosylation sites, these were added back to create the fully glycosylated form for that isolate. The fully glycosylated form was then mutated to remove the glycosylation site at Env positions specific for CONE proteins. For CONE 1, a glycan at the position $332(\mathrm{~N} 332 \mathrm{~S})$ or at the position 448 (N448S) was removed. For CONE 2, a single glycan in alpha-helix at the position 337 (N337/339S) was removed. For CONEs 4 and 5, the glycans N289S and N356/358S were removed, respectively. All positions are listed in reference to HXB2 HIV-1 viral strain. The envelope sequences of the isolates were pseudotyped on the HIV-1 subtype C viral backbone, and single-cycle infection virus was produced in HEK293T cells. Pre- and post-immunization sera were heat inactivated and diluted 1:10 in cell growth media. The inhibitory properties of post-immunization serum were compared to those of the pre-immunization serum for each animal. Data were analyzed and plotted using GraphPad Prism 6.0 software.

Reporting summary. Further information on experimental design is available in the Nature Research Reporting Summary linked to this article.

\section{Data availability}

The source data underlying Figs 2c, 3, 4 and Supplementary Figs 6, 7, 8, 9, 11 and 12 are provided as a Supplementary Source Data file. The coordinates of the designs C2S5 and C4S3 are available from the RCSB Protein Data Bank with the accession codes 6CFE and $6 \mathrm{CBU}$. A reporting summary for this Article is available as a Supplementary Information file. All other data supporting the findings of this manuscript are available from the corresponding authors (N.V.D. and R.S.) upon reasonable request.

Received: 4 July 2018 Accepted: 1 February 2019

Published online: 27 February 2019

\section{References}

1. Klein, F. et al. Antibodies in HIV-1 vaccine development and therapy. Science 341, 1199-1204 (2013)

2. Fraser, C. et al. Virulence and pathogenesis of HIV-1 infection: an evolutionary perspective. Science 343, 1243727 (2014).

3. Reitter, J. N., Means, R. E. \& Desrosiers, R. C. A role for carbohydrates in immune evasion in AIDS. Nat. Med. 4, 679-684 (1998).

4. Wei, X. et al. Antibody neutralization and escape by HIV-1. Nature 422, 307-312 (2003).

5. Stewart-Jones, G. B. et al. Trimeric HIV-1-Env structures define glycan shields from clades A, B, and G. Cell 165, 813-826 (2016).

6. Cao, L. et al. Global site-specific N-glycosylation analysis of HIV envelope glycoprotein. Nat. Commun. 8, 14954 (2017).

7. McCoy, L. E. \& Burton, D. R. Identification and specificity of broadly neutralizing antibodies against HIV. Immunol. Rev. 275, 11-20 (2017).
8. Pancera, M., Changela, A. \& Kwong, P. D. How HIV-1 entry mechanism and broadly neutralizing antibodies guide structure-based vaccine design. Curr. Opin. HIV AIDS 12, 229-240 (2017).

9. Crispin, M., Ward, A. B. \& Wilson, I. A. Structure and immune recognition of the HIV glycan shield. Annu Rev. Biophys. 47, 499-523 (2018).

10. Ping, L. H. et al. Comparison of viral Env proteins from acute and chronic infections with subtype $\mathrm{C}$ human immunodeficiency virus type 1 identifies differences in glycosylation and CCR5 utilization and suggests a new strategy for immunogen design. J. Virol. 87, 7218-7233 (2013).

11. McCoy, L. E. et al. Holes in the glycan shield of the native HIV envelope are a target of trimer-elicited neutralizing antibodies. Cell Rep. 16, 2327-2338 (2016).

12. Klasse, P. J. et al. Epitopes for neutralizing antibodies induced by HIV-1 envelope glycoprotein BG505 SOSIP trimers in rabbits and macaques. PLoS Pathog. 14, e1006913 (2018).

13. Klasse, P. J. et al. Sequential and simultaneous immunization of rabbits with HIV-1 envelope glycoprotein SOSIP.664 trimers from clades A, B and C. PLoS Pathog. 12, e1005864 (2016).

14. Yuste, E. et al. Glycosylation of gp41 of simian immunodeficiency virus shields epitopes that can be targets for neutralizing antibodies. J. Virol. 82, 12472-12486 (2008)

15. Gray, E. S. et al. Isolation of a monoclonal antibody that targets the alpha-2 helix of gp120 and represents the initial autologous neutralizing-antibody response in an HIV-1 subtype C-infected individual. J. Virol. 85, 7719-7729 (2011).

16. McLellan, J. S. et al. Structure of HIV-1 gp120 V1/V2 domain with broadly neutralizing antibody PG9. Nature 480, 336-343 (2011).

17. Briney, B. et al. Tailored immunogens direct affinity maturation toward HIV neutralizing antibodies. Cell 166, 1459-1470 (2016).

18. Jardine, J. et al. Rational HIV immunogen design to target specific germline B cell receptors. Science 340, 711-716 (2013).

19. Azoitei, M. L. et al. Computation-guided backbone grafting of a discontinuous motif onto a protein scaffold. Science 334, 373-376 (2011).

20. Zhou, T. et al. Transplanting supersites of HIV-1 vulnerability. PLoS One $\mathbf{9}$, e99881 (2014)

21. Zhu, C., Mowrey, D. D. \& Dokholyan, N. V. Computational protein design through grafting and stabilization. Methods Mol. Biol. 1529, 227-241 (2017)

22. Lee, J. H., Ozorowski, G. \& Ward, A. B. Cryo-EM structure of a native, fully glycosylated, cleaved HIV-1 envelope trimer. Science 351, 1043-1048 (2016).

23. Julien, J. P. et al. Crystal structure of a soluble cleaved HIV-1 envelope trimer Science 342, 1477-1483 (2013).

24. Pancera, M. et al. Structure and immune recognition of trimeric pre-fusion HIV-1 Env. Nature 514, 455-461 (2014).

25. Shirvanyants, D., Alexandrova, A. N. \& Dokholyan, N. V. Rigid substructure search. Bioinformatics 27, 1327-1329 (2011).

26. Ramachandran, S., Kota, P., Ding, F. \& Dokholyan, N. V. Automated minimization of steric clashes in protein structures. Proteins 79, 261-270 (2011).

27. Yin, S., Ding, F. \& Dokholyan, N. V. Eris: an automated estimator of protein stability. Nat. Methods 4, 466-467 (2007).

28. Rocklin, G. J. et al. Global analysis of protein folding using massively parallel design, synthesis, and testing. Science 357, 168-175 (2017).

29. Sanders, R. W. et al. HIV-1 neutralizing antibodies induced by native-like envelope trimers. Science 349, aac4223 (2015).

30. West, A. P. Jr. et al. Structural insights on the role of antibodies in HIV-1 vaccine and therapy. Cell 156, 633-648 (2014).

31. Correia, B. E. et al. Proof of principle for epitope-focused vaccine design. Nature 507, 201-206 (2014).

32. Impagliazzo, A. et al. A stable trimeric influenza hemagglutinin stem as a broadly protective immunogen. Science 349, 1301-1306 (2015).

33. Zhou, T. et al. A neutralizing antibody recognizing primarily N-linked glycan targets the silent face of the HIV envelope. Immunity 48, 500-513 (2018).

34. Crooks, G. E., Hon, G., Chandonia, J. M. \& Brenner, S. E. WebLogo: a sequence logo generator. Genome Res. 14, 1188-1190 (2004).

35. Schneider, T. D. \& Stephens, R. M. Sequence logos: a new way to display consensus sequences. Nucleic Acids Res. 18, 6097-6100 (1990).

36. Yin, S., Ding, F. \& Dokholyan, N. V. Modeling backbone flexibility improves protein stability estimation. Structure 15, 1567-1576 (2007).

37. Van der Spoel, D. et al. GROMACS: fast, flexible, and free. J. Comput. Chem 26, 1701-1718 (2005).

38. Huang, J. \& MacKerell, A. D. Jr. CHARMM36 all-atom additive protein force field: validation based on comparison to NMR data. J. Comput. Chem. 34, 2135-2145 (2013).

39. Zhu, C. et al. Slow and bimolecular folding of a de novo designed monomeric protein DS119. Biophys. J. 105, 2141-2148 (2013).

40. Otwinowski, Z. \& Minor, W. Processing of X-ray diffraction data collected in oscillation mode. Methods Enzymol. 276, 307-326 (1997). 
41. Adams, P. D. et al. PHENIX: a comprehensive Python-based system for macromolecular structure solution. Acta Crystallogr. D. Biol. Crystallogr. 66 213-221 (2010).

42. Winn, M. D. et al. Overview of the CCP4 suite and current developments. Acta Crystallogr. D. Biol. Crystallogr. 67, 235-242 (2011).

43. Chen, V. B. et al. MolProbity: all-atom structure validation for macromolecular crystallography. Acta Crystallogr. D. Biol. Crystallogr. 66 $12-21$ (2010).

44. Jung, Y. S. \& Zweckstetter, M. Mars-robust automatic backbone assignment of proteins. J. Biomol. NMR 30, 11-23 (2004).

45. Tamiola, K., Acar, B. \& Mulder, F. A. Sequence-specific random coil chemical shifts of intrinsically disordered proteins. J. Am. Chem. Soc. 132, 18000-18003 (2010).

46. Benhabbour, S. R. et al. In vitro and in vivo assessment of targeting lipid-based nanoparticles to the epidermal growth factor-receptor (EGFR) using a novel Heptameric ZEGFR domain. J. Control Release 158, 63-71 (2012).

47. Oyewumi, M. O. \& Mumper, R. J. Gadolinium-loaded nanoparticles engineered from microemulsion templates. Drug Dev. Ind. Pharm. 28, 317-328 (2002).

\section{Acknowledgements}

We thank Amy Davidson and the UNC DLAM facility for carrying out rabbit immunizations. We thank Dr. Michael Miley, Dr. Ash Tripathy, Dr. Brenda Temple, and UNC Macromolecular Interactions Facility and UNC Protein Expression \& Purification Facility staff. We thank Dr. Barton Haynes from Duke University for providing the gp120 proteins and Dr. Nancy Haigwood from Oregon Health \& Science University for providing the anti-gp140 rabbit IgG solution. We thank Prof. Rogier Sanders from Weill Cornell Medical College for sharing with us the original sequence of SOSIP BG505.664 protein. We thank Ewen Liu for help with the pseudovirus panel preparation. We thank Novavax, Inc for providing us with Matrix-M adjuvant. This work was supported by NIH Grants R01 AI102732 (to N.V.D. and R.S.), GM114015 and GM123247 (to N.V.D.). Infrastructure support from the UNC Center for AIDS Research (NIH award P30 AI50410) and the UNC Lineberger Comprehensive Cancer Center (NIH award P30 CA16068) is gratefully acknowledged.

\section{Author contributions}

C.Z., E.D., R.S. and N.V.D. devised the project. R.S. and N.V.D. conceived the main conceptual ideas and were in charge of overall direction and planning. C.Z. designed the computational models and performed the simulations. C.Z., E.M.F., S.L.U. and
J.M.F. carried out protein purification and biophysical experiments. C.Z. and H.K. obtained the crystal structures. C.Z., G.Y., and S.C. obtained and analyzed the NMR spectra. E.D., L.P., and O.C. performed characterization of rabbit antibody response to the immunogens (ELISA, IgG purification, western blots, neutralization assays). S.S.P. and S.R.B. prepared nanoparticle-conjugated immunogens. E.L.P. designed the HIV-1 pseudovirus panel. L.P.K. and E.S. assisted with rabbit sera processing and related experiments. C.Z., E.D., R.S., and N.V.D. wrote the paper with input from all authors.

\section{Additional information}

Supplementary Information accompanies this paper at https://doi.org/10.1038/s41467019-08876-w.

Competing interests: The authors declare no competing interests.

Reprints and permission information is available online at http://npg.nature.com/ reprintsandpermissions/

Journal peer review information: Nature Communications thanks the anonymous reviewers for their contribution to the peer review of this work.

Publisher's note: Springer Nature remains neutral with regard to jurisdictional claims in published maps and institutional affiliations.

cc (i) Open Access This article is licensed under a Creative Commons Attribution 4.0 International License, which permits use, sharing, adaptation, distribution and reproduction in any medium or format, as long as you give appropriate credit to the original author(s) and the source, provide a link to the Creative Commons license, and indicate if changes were made. The images or other third party material in this article are included in the article's Creative Commons license, unless indicated otherwise in a credit line to the material. If material is not included in the article's Creative Commons license and your intended use is not permitted by statutory regulation or exceeds the permitted use, you will need to obtain permission directly from the copyright holder. To view a copy of this license, visit http://creativecommons.org/ licenses/by/4.0/.

(c) The Author(s) 2019 